\title{
Ottawa needs to address social determinants of health, Canadians tell CMA
}

$\mathrm{C}$ anadians want the federal government to play a bigger role in reducing poverty and other social barriers to health, a Canadian Medical Association report reveals.

Participants in an online consultation and six town hall meetings held in cities across the country last winter and spring identified income as the top factor influencing health, and stressed the federal government's obligation to ensure adequate housing, nutrition and proper early childhood development for all Canadians.

"Together these determinants have a far greater impact on health outcomes than the health care system itself," thenCMA President Dr. Anna Reid said at a news conference July 30 in Ottawa, Ontario. "We know many of these health issues are largely out of the control of the individual and we also know that we can fix them with policy. ... It's too expensive not to invest up front."

The CMA report makes a dozen recommendations for action based on what Canadians said at the meetings. The top priority is a national plan to eliminate poverty.

"It's time for the federal government to come back to the table and help develop and implement a national plan that supports the provinces and territories that have already put povertyreduction plans in place," said Fred Phelps, executive director of the Canadian Association of Social Workers, at the news conference. "The roadmap exists, it's the political will at present that's lacking."

The report calls on the federal government to require health impact assessments as part of Cabinet decision-making, and to fund a major pilot of a refundable taxcredit program that would see participants receive a guaranteed minimum income to alleviate poverty.

It also urges cooperation with provincial and territorial governments to develop strategies to ensure access to affordable housing for low- and middleincome Canadians, establish a national

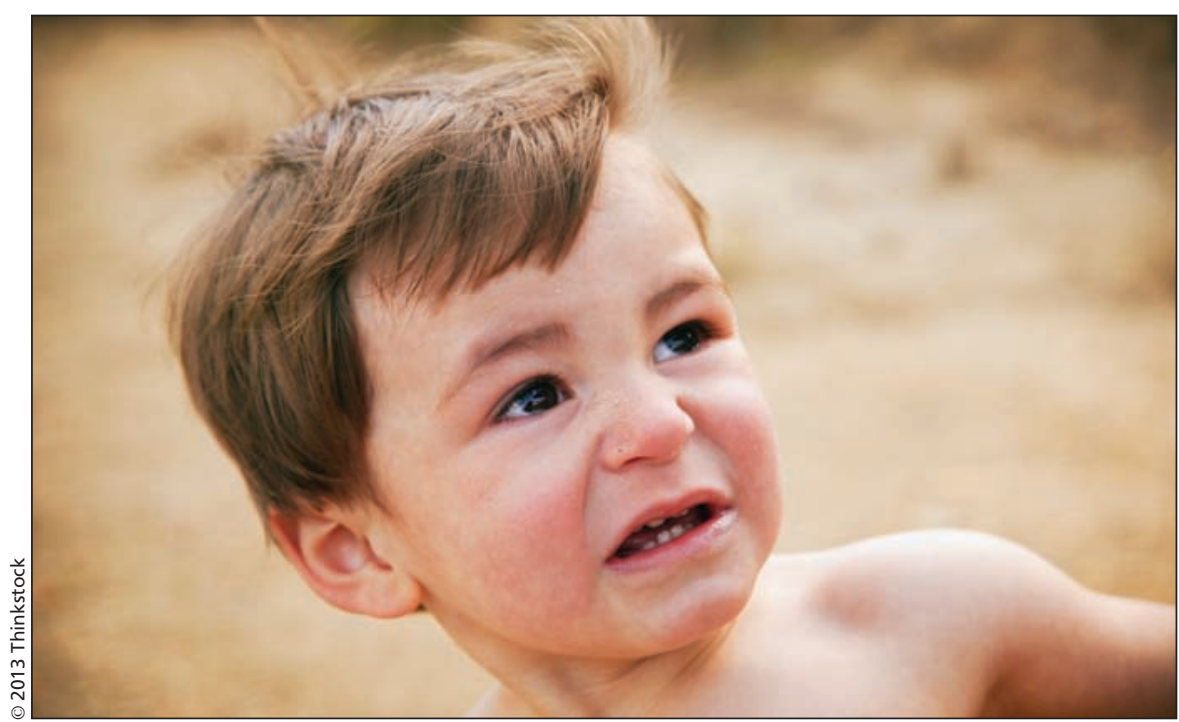

Canada compares poorly with its peers on indicators of success in early childhood development, states a CMA report. It estimates one in seven Canadian children lives in poverty.

food-security program, increase investment in early childhood development and create a national prescription drugcoverage program, among other recommendations.

For its part, CMA will develop tools to help physicians track the social factors influencing their patients' health and connect those patients to appropriate community resources.

"Some people ask me what poverty, housing and so on, have to do with physicians," Reid said. "While physicians are certainly not the experts on these social factors and how to fix them, we are the experts in caring for our patients and we see every day the downstream effect of the social determinants of health on patient wellbeing."

Some $20 \%$ of the $\$ 200$ billion spent annually on health care, and $50 \%$ of health outcomes, can be attributed to the social determinants of health, according to the report.

"There's a very strong link between a health population and a health economy, and people are starting to understand that poverty, the growing income gap and poor early childhood development are an economic drain on this country," Reid said. "If we're going to remain a prosperous country for all, we have to address these huge disparities."

Perhaps the "most glaring embarrassment" is Canada's poor performance compared to its peers on indicators of success in early childhood development, she added. "Other countries have very strong programs aimed at the early years from birth to before someone goes into kindergarten, involving such things as adequate daycare spaces, parenting programs and making sure young children have the nutrition they need. ... We know if we invest money in those things, we will get a good dollar return on that money invested.'

The report estimates that one in seven Canadian children lives in poverty, and new data reveal that one in six experiences food insecurity.

"It really hit me in a visceral way when we did these town halls around the country how widespread and deep these problems are," Reid said. "They're not isolated to Northern and remote and Aboriginal populations, they're here in downtown Ottawa, a few blocks from the prime minister's house." - Lauren Vogel, CMAJ

CMAJ 2013. DOI:10.1503/cmaj.109-4566 